\title{
Análise semiótico-psicanalítica de uma representação visual da burrice no ensino-aprendizagem de matemática
}

\author{
Semiotic-psychoanalytic analysis of a visual representation \\ of stupidity in mathematics teaching and learning
}

José Passos Lopes ${ }^{1}$

\begin{abstract}
Resumo: Este artigo objetiva analisar uma figura como representação visual ou signo da burrice no ensino-aprendizagem da matemática, que afetou 23 alunos de pedagogia com lembranças perturbadoras capazes de provocar falhas em seus testes de realidade. Analisaram-se dois formulários, um com associações livres da figura e outro com dissertações dos alunos, fazendo-se a leitura semiótico-psicanalítica dos dados. Os referenciais utilizados foram a teoria dos signos, com o estudo de Santaella das matrizes das linguagens e pensamento visual e verbal; as teorias dos interpretantes e da percepção de Peirce; e conceitos psicanalíticos. Os resultados apontaram uma maioria de associações referenciais opinativas. As palavras (remas) mais associadas foram burro, soma, errado, produzindo a proposição (dicissigno) opinativa: o burro soma errado. Concluiu-se que a opinião, de certa forma, expressa uma falha no teste de realidade, uma fuga de se enfrentar o desprazer que a figura causava.
\end{abstract}

Palavras-chave: Educação matemática. Semiótica -psicanalítica. Interpretação de imagens. Pedagogia.

\begin{abstract}
This article aims to analyze a picture as a visual representation or sign of stupidity in teaching and learning mathematics, which was carried out with 23 pedagogy students with disturbing memories that can cause flaws in their reality tests. Two forms were analyzed, one with free associations of the figure and one with dissertations from the students, making up the semiotic-psychoanalytic reading of the data. The references used were the theory of signs, with Santaella's study of the matrices of languages and thought (visual and verbal); Pierce's theories of interpretants and perception; and psychoanalytic concepts. The results showed a majority of opinionated reference associations. The most associated words (rhemes) were donkey, add, wrong, producing the opinionated (dicisign) proposition: the donkey adds up wrong. It was concluded that this, shows a flaw in reality testing, as subjects escape from facing up to the displeasure that the figure caused.
\end{abstract}

Keywords: Mathematics education. Semiotic psychoanalytic. Image interpretation. Pedagogy.

\footnotetext{
${ }^{1}$ Universidade Paulista (UNIP), Instituto de Ciências Humanas, Santos, SP, Brasil. E-mail: <jspl@uol.com.br>.
} 


\section{Introdução}

Este trabalho analisa uma representação visual da burrice na matemática, recorte de uma pesquisa que procurou entender o processo de pensamento matemático de alunos de pedagogia. Encontraram-se elementos de que a burrice no ensino-aprendizagem da matemática é construída. Entre outros resultados, percebeu-se que uma das figuras que representava visualmente a burrice em matemática (Figura 1), em um dos formulários, trouxe respostas que informavam perturbações nos alunos pesquisados. Questionou-se o porquê disso. A hipótese formulada foi a de que a figura, representação visual da burrice no ensino-aprendizagem da matemática, teria induzido falhas no teste de realidade dos alunos.

Pouquíssimas são as pesquisas que tratam do tema da burrice no ensino-aprendizagem da matemática. Imenes (1989 apud SIGNORINI, 2007, p. 16) explica: "Em resumo, quem não aprende as outras matérias é, no máximo, considerado vagabundo; mas quem não aprende matemática é tachado de burro. Esse aspecto peculiar ao ensino de matemática é muito forte." Becker (2012, p. 265) argumenta que o senso comum vê a aprendizagem em razão do ensino. "Se alguém dispõe de ensino e não aprende é burro, isto é, não tem talento ou, o que dá no mesmo, não é dotado geneticamente de inteligência. Nasceu com alguma parte do genoma comprometido, estragado, debilitado. Por isso não adianta ensinar a tal pessoa."

Avaliações nacionais e internacionais mostram o baixo desempenho dos alunos brasileiros em matemática. Vasconcellos e Bittar (2006) e Biajone (2006) apontaram que alunos procuram o curso de pedagogia por ser o que não necessita aprender matemática. A partir dessas considerações, constata-se a necessidade de se conhecer a representação que os futuros pedagogos fazem da matemática.

O exame dos dados da Figura 1 evidenciou as lembranças desprazerosas nos alunos. A análise psicanalítica auxiliou no rastreamento do acontecido, usando-se o conceito de teste de realidade. As palavras freudianas auxiliam na justificativa dessa análise: "O alcance e a significação desse desprazer em recordar impressões penosas parecem merecer o mais cuidadoso exame psicológico" (FREUD, 1987, p. 237). Também foram utilizados para esse rastreamento a teoria dos interpretantes e da percepção peirceana proporcionando, assim, maior relevância para este estudo.

Figura 1. Representação visual da burrice

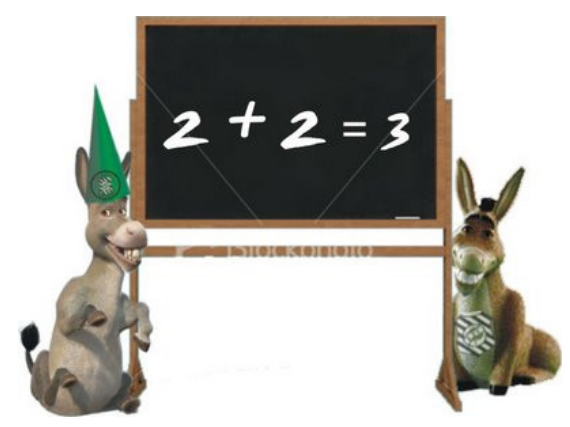

Fonte: Disponível em: <http://carpinteiroslimpos.blogspot.com.br/>. Acesso em: 17 dez. 2015. 
Análise semiótico-psicanalítica de uma representação visual da burrice ...

Este artigo objetivou analisar a Figura 1 como representação visual, signo, da burrice no ensino-aprendizagem da matemática, que afetou os alunos com lembranças perturbadoras capazes de provocar falhas em seus testes de realidade.

A pesquisa efetivou-se em uma universidade privada com 23 alunos. Dezoito mulheres com faixa etária variando de 25 a 54 anos e cinco homens com idade entre 26 e 54 anos. Foram utilizados três formulários: um com nove figuras de matemática para associação livre, em que eles deveriam escrever em três linhas, sob cada figura, três palavras. O segundo trazia a frase "Eu e uma aula de matemática", para que fizessem um desenho. O terceiro solicitava que dissertassem a partir do tema "Minha história com a matemática". Para este artigo, somente foram usados o formulário das associações e a dissertação. Os dados foram analisados mediante a leitura semiótico-psicanalítica. As referências teóricas usadas foram a teoria dos signos, com o estudo de Santaella (2005a) das matrizes das linguagens e pensamento visual e verbal; as teorias dos interpretantes e da percepção de Peirce e conceitos psicanalíticos.

\section{A burrice no ensino-aprendizagem de matemática}

Para o senso comum, não saber disciplinas como português, história, geografia, por exemplo, é questão de falta de estudo: se o aluno estudar, aprenderá. Para a matemática, não: seria questão de inteligência, dom ou predisposição genética. Especificando: as outras disciplinas não foram aprendidas por razões de vagabundagem; a matemática, por razões de burrice, geneticamente determinadas. Becker (2012) anota que os professores assimilaram, também, essa forma de pensar. Professam uma epistemologia do senso comum, fundamentada em uma epistemologia empirista que se ampara na epistemologia apriorista; do senso comum, pois surgem de maneira espontânea, sem que se tenha pensado a respeito. Trata-se de uma união bastarda, responsável por um preconceito epistemológico efetivado pela escola: "a capacidade inteligente é imutável e igual para todos. Todos podem aprender quaisquer coisas desde que bem ensinadas. Se o professor ensinar bem, o aluno, se tiver dado conta dos pré-requisitos, só poderá aprender" (BECKER, 2012, p. 211). A criança aprende porque é inteligente (apriorismo) ou em razão dos estímulos suficientes (empirismo). Em um caso, a inteligência é determinada geneticamente (evidentemente, a burrice também); no outro, o professor em sua excelência sabe estimular o bom aluno.

Chaves (2001, p. 3) questiona: De onde vem a burrice? Para ela, "a burrice pode ser vista como uma mensagem cifrada, semioticamente mediada, dirigida ao outro como um significante, pois muitas das dificuldades de aprendizagem aparecem como uma forma de pedir ajuda". Cita o ato falho de uma aluna que junta aborrecimento com burrice, gerando emburrecimento. A Figura 1, aqui analisada, busca compreender o pensamento dos alunos pesquisados sobre a matemática que parece traduzir o aborrecer do ensino-aprendizagem da matemática: a leitura da imagem fala da burrice, do emburrecimento.

\section{O signo}

A semiótica fala em signos-pensamentos, e Peirce (1977, p. 269, grifos do autor) diz que "sempre que pensamos, temos presente na consciência algum sentimento, imagem, concepção 
ou outra representação que serve como signo." O autor pondera que, no momento em que pensamos, um signo tem três referências: "é um signo para algum pensamento que o interpreta; é um signo de algum objeto ao qual, naquele pensamento, é equivalente; terceiro, é um signo, em algum aspecto ou qualidade, que o põe em conexão com seu objeto". A este artigo interessa principalmente a primeira referência, ligada ao interpretante.

O fenômeno, na visão peirceana, é entendido como "tudo aquilo, qualquer coisa, que aparece à percepção e à mente” (SANTAELLA, 2005b, p. 7). A fenomenologia apresenta três elementos formais, universais: primeiridade, secundidade e terceiridade. Além disso, as leis do pensamento necessitam do estudo dos signos. Três são as tricotomias sígnicas em Peirce: a primeira trata da natureza material do signo, que pode ser um qualissigno, um sinssigno ou um legissigno; a segunda tricotomia mostra a relação existente entre signo e objeto, em que um signo pode ser um ícone, um índice ou um símbolo; a terceira, que fundamentou este estudo, estatui a relação signo e interpretante, podendo ser um rema, dicissigno ou argumento. "Trata-se de signos que se propõem representar algo do mundo visível ou, em caso-limite, apresentarem-se a si mesmos como signos" (SANTAELLA, 2005a, p. 186). Especificamente, remas e dicissignos ou dicentes serão utilizados: o rema, na sua primeiridade, é um interpretante hipotético, não produz afirmações, sendo uma palavra. O dicissigno ou dicente, signo de existência real, veicula informação. É uma proposição sendo "a unidade mínima para exprimir idéias que podem ser ou verdadeiras ou falsas. Consiste de uma combinação de ao menos um argumento (sujeito) e um predicado, por exemplo, do tipo 'A é B"' (NÖTH, 1995, p. 88). O argumento significa o discurso argumental.

A análise propõe uma semiose, "ação do signo. A ação que é própria ao signo é a de determinar um interpretante." (SANTAELLA, 2005b, p. 13). Seria “a ação de ser interpretado em um outro signo, pois o interpretante tem sempre a natureza de um signo (mesmo que seja um signo rudimentar, um sentimento, por exemplo, ou uma percepção ou uma ação física ou mental)." (SANTAELLA, 2005b, p. 13). Para se entender "a noção de interpretante, isto é, aquilo que o signo produz como efeito em uma mente potencial ou atual, é preciso considerar que o interpretante tem vários níveis de realização: o imediato (primeiridade), o dinâmico (secundidade) e o final (terceiridade)" (SANTAELLA, 2005b, p. 128). O imediato é sua interpretabilidade, seu potencial interpretativo, antes que haja um intérprete. $O$ dinâmico resulta no efeito efetivo causado pelo signo em um intérprete. O final ocorre somente se uma investigação prolongada se fizer no signo. Mas o dinâmico se subdivide em três subníveis: o efeito emocional se relaciona à qualidade de sentimento despertada no intérprete: impressões mais ou menos definidas, flutuantes, variáveis, o ícone está mais afeito a ele. O efeito energético se produz mediante uma reação ativa no receptor. "Índices tendem a produzir esse tipo de interpretante com mais intensidade, pois os índices chamam nossa atenção, dirigem nossa retina mental ou nos movimentam na direção do objeto que eles indicam" (SANTAELLA, 2005b, p. 25). O efeito lógico ocorre se a interpretação do signo acontece mediante uma regra interpretativa. É mediante o símbolo que acontece.

\section{O teste de realidade}

[...] Desde o início, quando a vida nos submete à sua rígida disciplina, dentro de nós se levanta uma resistência contra a inflexibilidade e monotonia das leis do pensamento e contra as exigências do teste de realidade. A razão se 
torna o inimigo que nos priva de tantas possibilidades de prazer. Descobrimos quanto prazer nos dá retrair-nos dela, temporariamente ao menos, e nos entregar aos atrativos do absurdo. [...] (FREUD, 1976a, p. 47).

A Figura 1 evoca lembranças perturbadoras e, ante elas, melhor fugir. Nem sempre se sabe se o pensado é fruto da realidade ou imaginação. Para se distinguir o percebido de suas representações, mundo interno do externo, Freud propôs o teste de realidade. Usa-se a fantasia, que tem estrutura similar à do inconsciente, como forma de fuga, pontua Jorge (2010, p. 57). Os processos inconscientes não atentam para o teste de realidade, laboram ativados pelo princípio de prazer. O pensamento freudiano explica a gênese do processo no bebê, que "alucina o objeto da necessidade (vivida por ele com mal-estar) que lhe proporcionaria prazer ao satisfazê-la" (JORGE, 2010, p. 57), mas “a pura alucinação não é jamais capaz de satisfazer a necessidade e leva à substituição do princípio de prazer pelo princípio de realidade, que governa as instâncias conscientes.” (JORGE, 2010, p. 57). A vida, com suas exigências, determina o fim da dominância do princípio de prazer. No seu lugar, emerge o princípio de realidade, e o teste de realidade objetiva averiguar toda representação que surge no sujeito. Para Figueiredo (2006), fundamentado na visão kleiniana, normalidade e patologia se distinguem na maneira como se lida com as fantasias inconscientes. A normalidade, "consistindo em admitir, expressar, simbolizar e transformar estes elementos em contato com a experiência, e as patologias caracterizando-se pela operação de mecanismos de defesa contra elas" (JORGE, 2010, p. 57). O teste de realidade não se conceberia como conflito entre a percepção e a fantasia, em razão de não haver percepção sem a operação de fantasias inconscientes. Ele prefere o termo processamento da realidade para o processo entre a fantasia e a percepção.

A falha do teste de realidade não é responsável pelos quadros patológicos. O que ocorre é justamente o contrário. Há algo que desativa o teste de realidade. Algo que se torna insuportável para o ego leva ao rompimento com a realidade. (JORGE, 2010, p. 57).

Isso faz com que ocorra "o desinvestimento do sistema de percepções, Cs., isto é, o ego retira a atenção e deixa vir uma nova catexia a partir do interior que leva à psicose" (PORCHAT, 2005, p. 118).

A autora anota que, para Freud, o teste de realidade seria adaptações por que passa o aparelho psíquico para processar o princípio de realidade. Para ela, é "um conceito que abrange um conjunto de mecanismos e não apenas um único” (PORCHAT, 2005, p. 33). Mas o teste de realidade não abrange todos os processos do aparelho psíquico: a fantasia escapa a ele. $\mathrm{O}$ freio da satisfação alucinatória no bebê, no adulto continua a operar a fim de discriminar entre mundo interno e externo, pertencendo ao sistema consciência-percepção.

Segundo Gabbi Jr., a defesa primária pode ser entendida como uma alucinação negativa do objeto hostil. A vivência de dor deixou como resíduo uma inclinação para negar a existência do objeto hostil. No caso da repetição da vivência, evita-se a imagem recordativa do objeto hostil, como se ela não existisse. $\mathrm{O}$ aparelho psíquico põe em funcionamento um mecanismo 
equivalente ao da fuga da dor, ou seja, de escoamento rápido. No entanto, o desprazer causado pela catexia dessa imagem é entendido como proveniente de um objeto externo. A repressão tem como fundamento um objeto externo que impõe uma grande quantidade ao aparelho psíquico. [...] (PORCHAT, 2005, p. 72).

Para a autora, os elementos que compõem o teste de realidade são: inibição, atenção, o julgar, ação motora e o pensar. A inibição interrompe o processo psíquico que redundaria em alucinação, levando em conta a realidade. A atenção possibilita a consciência dos objetos externos, pois investe no sistema percepção-consciência. O julgar discrimina irreal (representação subjetiva) e real (o mundo externo), ele antecede o processo de pensar, referente ao modo de funcionamento do processo secundário. A ação motora leva do pensar ao agir com a capacidade de modificar a realidade.

\section{A figura: leitura semiótica}

"A teoria semiótica nos habilita a penetrar no movimento interno das mensagens, o que nos dá a possibilidade de compreender os procedimentos e recursos empregados nas palavras, imagens, diagramas, sons e nas relações entre eles" (SANTAELLA, 2005b, p. 48). Ler semioticamente é analisar o fenômeno, contemplando, discriminando e generalizando em correlação com as categorias da primeiridade, secundidade e terceiridade. Contemplar significa tornar disponível aos sentidos. Para tanto, trabalha-se com a gramática especulativa ou teoria e classificação dos signos, possibilitadora da leitura da mensagem manifesta no signo.

$\mathrm{Na}$ leitura da imagem, busca-se sua referencialidade. A Figura 1 transmite uma mensagem e, para sua análise, será usada a leitura de sua comunicação não verbal, índices que ajudam a compor a imagem. Rector e Trinta (1986) analisam a estrutura da comunicação não verbal com a proxêmica, que estuda o uso e o sentido social do espaço, possibilitando que se ajuíze a distância interpessoal, a orientação corporal; grau de proximidade e afastamento corporais; toques, contatos visuais. Estuda, portanto, o uso do espaço humano na sua estrutura, concepção, se em ambiente construído ou natural e nas interações sociais, suas distâncias inconscientes ou conscientes. Estas seriam quatro: distância intima $(0-50 \mathrm{~cm})$ - proximidade corporal e envolvimento físico altos; distância pessoal (0,5-1,20 m) - proximidade seria relativa ao alcance da mão; distância social (1,20-3,60 m) - sem contato físico, apenas visual; distância pública - sem qualquer contato individual visual. Os autores também analisam o jogo fisionômico: fechamento e abertura dos olhos, como as sobrancelhas se posicionam (contração, elevação), o volver dos olhos, o movimento da boca, o entreabrir dos lábios etc. Lemos (2006), na codificação que faz dos sistemas de comunicação não verbal, assinala os movimentos dos olhos - expressões faciais e seus movimentos oculares expressam intensivamente estados emocionais dos emissores. Principalmente os olhos comunicam, porém, as mensagens dependem da duração, direção e qualidade do olhar. Também artefatos - objetos do cenário e acessórios informam sobre as pessoas. 
Análise semiótico-psicanalítica de uma representação visual da burrice ...

Figura 2. Eixos e diagonais

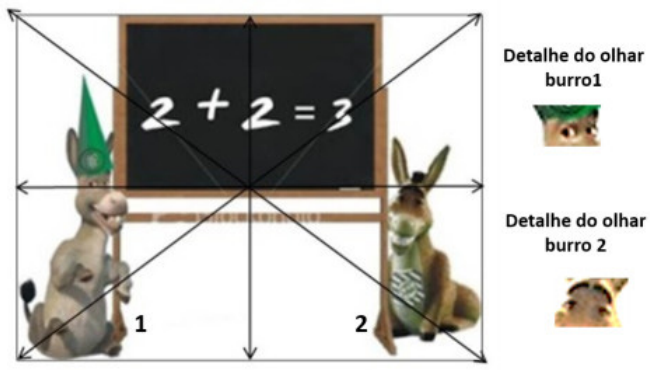

Fonte: adaptado de <http://carpinteiroslimpos.blogspot.com.br/>. Acesso em: 17 dez. 2015.

A Figura 1 mostra uma lousa com uma adição errada: $2+2=3$. Ladeando a lousa, dois burros. Os burros foram antropomorfizados. A charge é uma montagem com imagens do Burro do Shrek ${ }^{2}$. Não foi possível descobrir a origem da lousa. Não se sabe se a composição visual foi planejada com conhecimentos técnicos ou feita intuitivamente. Percebe-se uma ironia em relação à matéria do jornal Diário Catarinense "Figueira contraria matemática e mantém ascensão na tabela" (FIGUEIRA..., 2008). Na cabeça do primeiro Burro do Shrek, há um chapéu de burro com o escudo do time de futebol Figueirense; o mesmo escudo foi colocado no peito do segundo burro. Os demais sites que utilizaram a charge o fizeram num contexto de simbolização da burrice.

Arnheim (1990, p. 17) fala da chave mestra para a composição visual: "combinações de formas definidas, organizadas numa estrutura englobante". Um esquema de composição se fundamenta em duas tendências: a cêntrica e a excêntrica. Centricidade e excentricidade se baseiam em relações espaciais. Há o poder do centro, mas para que uma composição seja dinâmica, tais sistemas devem interagir, a fim de que haja equilíbrio e harmonia.

A Figura 1 é um retângulo. Para Arnheim (1990), espaços retangulares trazem a força da centricidade, pois envolvem o meio e criam uma grelha excêntrica de vetores cruzados. A lousa é um retângulo dentro de outro retângulo, colocado na parte superior central (Figura 2). Parece suspensa, desafiando a força da gravidade e o peso visual centra-se na parte superior e rompe a simetria com a horizontalidade da parte inferior. Arnheim (1989, p. 4) diz que "a experiência visual é dinâmica", já que, no perceber visual, "há uma interação de tensões dirigidas". A charge apresenta elementos de maior peso na horizontalidade, mas o equilíbrio compositivo pode ser visto na verticalidade, principalmente do burro à esquerda e nos apoios laterais da lousa. A composição não oferece qualquer surpresa visual estrutural, pois a posição de seu centro geométrico coincide com o da figura, mas a lousa, na cor preta, provoca um aguçamento. A charge aponta uma tensão visual máxima em relação ao eixo horizontal, dando mais peso à

\footnotetext{
${ }^{2}$ A postagem mais antiga encontrada foi a do site Avainet (disponível em: < http://avainet.blogspot.com. br/2008/07/contrariando-matemtica.html>. Acesso em: 17 jan. 2017).
} 
lousa colocada na parte superior da figura. O peso "significa capacidade de atrair o olho", e, em razão disso, possui "uma enorme importância em termos de equilíbrio compositivo" (DONDIS, 1991, p. 41). Há um peso também conferido pela cor negra da lousa impregnado de significado simbólico negativo. Na lousa se encontra o microtema, denominado por Arnheim (1990) como a versão menor, sintética do tema da representação visual, em geral situado próximo ao centro da representação. O microtema da charge é a burrice, pois é erro elementar, conta-se nos dedos dois mais dois; não tem como errar.

Analisando a comunicação não verbal, os burros, do ponto de vista da proxêmica, mantêm distância intima com a lousa, pois estão basicamente encostados nela. Os artefatos apresentam como acessórios o chapéu de burro e o escudo no peito do burro da direita; como objetos, apenas a lousa compõe o cenário: mas ela é imperiosamente dominante. Quanto ao jogo fisionômico, os dois burros estão sorrindo e nos movimentos dos olhos se nota a direção dos seus olhares assim como a qualidade do olhar.

Segundo Ramos (1982), Eisenstein defendia, para o cinema, uma visão dialética entre planos que redundaria na significação. Montagem era palavra-chave para ele, e montar significa colar planos em sequência. $O$ diretor também defendia que o espectador deveria reconhecer os personagens pela observação de seu rosto. Fundamentado em Kuleshov, cuja experiência mais importante foi a montagem de um grande plano do rosto do ator Mosjoukine, que havia sido retirado de um filme de Bauer, com outro plano de um prato de sopa; em seguida, fez a montagem desse mesmo plano do rosto do ator com outro aparecendo um caixão de uma criança; e um terceiro plano com o mesmo rosto e outro em que aparecia uma atriz seminua em pose sensual. A plateia reagiu à projeção do conjunto unanimemente, atribuindo ao ator excelência de desempenho, expressando, sucessivamente, sentimentos de fome, dor e desejo. "Kuleshov demonstrava assim que a significação de uma sequência pode depender exclusivamente de relacionação subjectiva que o espectador faz de planos diversos que, separadamente, a não possuem nem sequer parceladamente”. (RAMOS, 1982, p. 22).

$\mathrm{Na}$ charge, a colagem se impregna do microtema: a burrice. Os artefatos podem modificar o sorriso e o olhar dos burros. Seus sorrisos, dependendo do leitor da imagem, do teste de realidade, podem configurá-los como de dois imbecis. Barthes (1984, p. 13), estudando a mensagem fotográfica, afirma que "a emissão e a recepção da mensagem dependem ambas de uma sociologia: trata-se de estudar os grupos humanos, de definir motivos, atitudes, e tentar ligar o comportamento desses grupos à sociedade total de que fazem parte." Ele fala ainda, no caso de desenhos, pintura, etc., do estilo de reprodução, um segundo sentido, "cujo significante é um certo 'tratamento' da imagem sob a acção do criador, e cujo significado, quer estético, quer ideológico, remete para uma certa 'cultura' da sociedade que recebe a mensagem”" (BARTHES, 1984, p. 15, grifos do autor). Aqui se encontram elementos para se pensar a "cultura" da burrice no ensino-aprendizagem da matemática.

Esse detalhado olhar semiótico da Figura 1 capturou índices da charge que ajudam a mapear o discurso da burrice nessa representação visual. Mas se refinou ainda mais o processo mediante a teoria dos interpretantes. Santaella (2005b, p. 23) anota: "A teoria dos interpretantes de Peirce é um conjunto de conceitos que fazem uma verdadeira radiografia ou até uma microscopia de todos os passos através dos quais os processos interpretativos ocorrem". Também com a teoria da percepção peirceana, e sua "estrutura lógica similar à da linguagem. A percepção se constitui em uma semiose específica, quer dizer, na percepção também há ação sígnica. Tanto 
é assim que o juízo perceptivo funciona como signo" (SANTAELLA, 2005a, p. 206). As três matrizes da linguagem e pensamento - sonora, visual e verbal - codificadas pela autora se estribam na fenomenologia peirceana em que pensamento, signos e percepção são indistinguíveis.

A autora classifica a linguagem visual dentro da matriz da secundidade e não da primeiridade, como se costuma fazer. Nesse contexto, entende-se que as figuras no formulário de pesquisa, antes que os alunos as percebessem, seriam um hipoícone. Peirce (1977, p. 64, grifo do autor) escreve: "Qualquer imagem material, como uma pintura, é grandemente convencional em seu modo de representação, porém em si mesma, sem legenda ou rótulo, pode ser denominada hipoícone". Contudo, tão logo os alunos associam as palavras (remas) a elas, tornam-se dicissignos, pois Peirce assinala que uma figura com um nome escrito embaixo é uma proposição. Foi estabelecida uma conexão dinâmica entre o visto e o descrito, criando um traço de indexicalidade. Na fotografia, essa conexão com o objeto fotografado se mostra física, dinâmica e existencial porque fotografar é gravar com a luz: tecnicamente, obtém-se o registro de uma imagem pela luz refletida por um objeto e o obturador da câmara controlando a entrada dessa luz; por isso são genuinamente indiciais. É pura secundidade, pois há uma relação existencial entre a fotografia e o fotografado. Outras representações visuais figurativas, pintura, gravura etc. são índices degenerados, porque, nesse caso, há referencialidade na secundidade. A Figura 1 reproduz algo do mundo real (burros e lousa). Usando palavras de Santaella (2005a, p. 198): "imagens figurativas, especialmente quando reproduzem algo visível no mundo lá fora, resultam de um efeito psicofísico que um objeto provoca naquele que produz a imagem”.

O interpretante do rema (palavras que os alunos associaram), apenas conjectural, é primeiridade. Porém, o interpretante do dicissigno, a proposição formada pelos remas, é uma secundidade e pode ser interpretado pela informação que produz. Santaella (2005a, p. 201) diz: "Uma vez que fornece informação sobre algo existente, o discente é puramente referencial, reportando-se a algo fora dele. Desse modo, seu interpretante terá uma relação existencial, real com o objeto do dicente, tal como este mesmo tem". E ainda:

[...] formas figurativas dizem respeito às imagens que basicamente funcionam como duplos, isto é, transpõem para o plano bidimensional ou criam no espaço tridimensional réplicas de objetos preexistentes e, o mais das vezes, visíveis no mundo externo. São formas referenciais que, de um modo ou de outro, com maior ou menor ambigüidade, apontam para objetos ou situações em maior ou menor medida reconhecíveis fora daquela imagem. Por isso mesmo, nas formas figurativas, é grande o papel desempenhado pelo reconhecimento e pela identificação que pressupõem a memória e a antecipação no processo perceptivo. Nessas formas, que buscam reproduzir o aspecto exterior das coisas, os elementos visuais são postos a serviço da vocação mimética, ou seja, produzir a ilusão de que a imagem figurada é igual ou semelhante ao objeto real. (SANTAELLA, 2005a, p. 227).

A Figura 1 pode ser classificada no que Santaella (2005a, p. 233) denomina registro imitativo, exemplificado por desenhos, pinturas, gravuras. Nelas, a função da imagem como mimese se acentua, "pois o artista busca reproduzir o objeto em todos os seus detalhes com o máximo de fidelidade. Essas imagens se enquadram na modalidade da 'Figura como registro' 
porque elas reproduzem algo que está fora delas, através de uma conexão existencial”. Imitam em razão da busca da fidelidade ao representado.

Ao fazer a varredura visual da Figura 1, o aluno a interpretou. $O$ interpretante dinâmico mostra o processo. Primeiro seu efeito emocional: ao se deparar com a charge, ela desperta a qualidade do sentimento, o choque das impressões não muito claras ou definidas, percebe a imagem em sua iconicidade. Conforme suas experiências colaterais com a matemática, reagirá ao efeito energético de forma ativa ou fugindo ao que a imagem lhe significa. O efeito lógico ocorrerá de maneira mais eficaz, ou não, se ele conseguir simbolizar todo o processo.

A teoria da percepção ajuda a esmiuçar melhor o processo. Para Santaella (2005a), a teoria peirceana da percepção é triádica: Percepto é estímulo: a coisa chega à percepção do sujeito que não pode evitar percebê-la. Os sentidos, como janelas abertas, captam tudo. Imediatamente, o percepto se transforma em percipuum: o sistema sensório filtra esse estímulo de certa maneira, traduzindo-o em percipuum. Essa conversão acontece em três níveis: (1) mera qualidade de sentimento; (2) modo surpreendente; (3) hábito interpretativo. No nível 1, assoma à consciência do percebedor "uma onda vaga e indefinida de sentimento" (SANTAELLA, 2005a, p. 108), a primeiridade. "Produz-se, no campo perceptivo, uma espécie de fusão entre o percebedor e o percebido. A percepção é imediata na sua imediaticidade, pura presentificação que borra os limites entre o percepto e percipuum" (SANTAELLA, 2005a, p. 108). No nível 2, o percepto surge como o "inesperado produzindo o efeito da surpresa e mesmo do choque. O percipunm surge como reação instantânea não mediada pela ação do hábito” (SANTAELLA, 2005a, p. 108). Para o terceiro nível, aparece o juízo perceptivo.

[...] Tão logo o percepto é recebido sob a forma de percipuum, este é imediatamente capturado pelos esquemas gerais de interpretação com que o ser humano está provido. Esse elemento de generalidade corresponde aos princípios condutores ou hábitos mentais que regulam a formação do juízo de percepção. É através do juízo perceptivo que reconhecemos aquilo que é percebido. O percepto é algo externo que bate insistentemente à porta de nossa percepção. Ele é mudo, pois não dispõe de nenhuma generalidade. São os esquemas conceituais que trazem consigo os elementos interpretativos gerais que permitem a identificação e o reconhecimento do percepto. (SANTAELLA, 2005a, p. 108).

A Figura 1 (o estímulo), mediante as associações feitas pelos alunos, ao ser percebida (o percepto) foi filtrada pelo sistema sensório e convertida em percipuum em seus três níveis. Os alunos tinham um objetivo: escrever três palavras sob as figuras. Olhar uma figura e escrever a respeito dela é referenciá-la: é uma descrição, que, "como um processo de análise do objeto descrito, pode ser considerada como a verbalização de um processo linear de observação, de um olhar que se detém no objeto [...]" (CATHARINO, 2007, p. 50). Inclusive porque, "antes de se descrever, é preciso saber olhar, observar o descrito.” (CATHARINO, 2007, p. 55). Baseado em Santaella (2005a) e Catharino (2007), viu-se a descrição como competência explicativa e verbal do observado. Os remas produzidos pela associação livre criam um processo de nomear, substantivar, adjetivar. Ao se nomear, determina-se uma identificação, pois se transforma o que se observa em um existente, já que o intérprete procura diferenças e semelhanças. Além disso, 
qualifica, pois o intérprete-observador testemunha o que vê. É um processo objetivo em busca da referencialidade e procura estar bem próximo da realidade; contudo, pode se transformar em subjetivo se houver emissão de juízos de valor.

Santaella (2005a) analisa a descrição como Goodman a vê, ao compará-la com a representação pictórica. Para ela, a descrição é uma submodalidade da matriz verbal, mas o retrato visual, assim como a descrição verbal, funcionam denotativamente. Há interpenetrações e interfaces nas três matrizes, já que não existem linguagens puras. Para o pensamento peirceano, "antes de tudo, a descrição se enquadra na classe das proposições. Segundo Peirce, uma proposição particular fornece uma descrição geral de um objeto e afirma que um objeto a que essa descrição se aplica ocorre no universo do discurso" (SANTAELLA, 2005a, p. 294).

\section{Resultados e discussão}

Os alunos pesquisados produziram os seguintes remas descritos no Quadro 1.

Quadro 1. Palavras escritas sob a Figura 1

\begin{tabular}{|c|c|c|c|c|c|}
\hline $\begin{array}{l}\text { Código } \\
\text { do } \\
\text { aluno }\end{array}$ & Palavras & $\begin{array}{l}\text { Código } \\
\text { do } \\
\text { aluno }\end{array}$ & Palavras & $\begin{array}{l}\text { Código } \\
\text { do } \\
\text { aluno }\end{array}$ & Palavras \\
\hline AN001 & $\begin{array}{l}\text { Matemática (RI) } \\
\text { Animação (NR) } \\
\text { Incentivo (NR) }\end{array}$ & NA02 & $\begin{array}{l}\text { Ridicularizando o } \\
\text { aluno (RO) } \\
\text { Não sabe matemática } \\
\text { (RO) } \\
\text { Professor não soube } \\
\text { ensinar (RO) }\end{array}$ & A1301 & $\begin{array}{l}\text { Ensino }(\mathrm{RI}) \\
\text { Aprendizagem (RI) } \\
\text { Porque (RDE) }\end{array}$ \\
\hline AN003 & $\begin{array}{l}\text { Simples (RO) } \\
\text { Soma (RD) } \\
\text { Facilidade (RO) }\end{array}$ & NA03 & $\begin{array}{l}\text { Burros (RD) } \\
\text { Conta errada (RD) } \\
\text {------ }\end{array}$ & A1302 & $\begin{array}{l}\text { Rotulação (RO) } \\
\text { Conhecimento } \\
(\mathrm{NR}) \\
\text { Atenção (NR) }\end{array}$ \\
\hline AN004 & $\begin{array}{l}\text { Dois burros (RD) } \\
\text { Não sabe somar (RO) } \\
\text { Quadro negro (RD) }\end{array}$ & NA04 & $\begin{array}{l}\text { Somando errado (RO) } \\
\text { Burro (RD) } \\
\text { Quadro negro (RD) }\end{array}$ & A1303 & $\begin{array}{l}\text { Excluído (RO) } \\
\text { Rejeitado (RO) } \\
\text { Difícil (RDE) }\end{array}$ \\
\hline AN005 & $\begin{array}{l}\text { Errado (RD) } \\
\text { Burro (RD) } \\
\text { Adição (RD) }\end{array}$ & NA05 & $\begin{array}{l}\text { Escola (RI) } \\
\text { Formação (RI) } \\
\text { Qual aprendizagem } \\
\text { (RO) }\end{array}$ & A1304 & $\begin{array}{l}\text { Humor (RI) } \\
\text { Matemática (RI) } \\
\text { Conceito (NR) }\end{array}$ \\
\hline AN007 & $\begin{array}{l}\text { Números (RD) } \\
\text { Aprendizagem errada } \\
\text { (RO) } \\
\text { Falso entendimento } \\
\text { (RO) }\end{array}$ & NA06 & $\begin{array}{l}\text { Não entende (RO) } \\
\text { Não sei (RDE) } \\
\text { Eles não sabem (RO) }\end{array}$ & A1305 & $\begin{array}{l}\text { Soma (RD) } \\
\text { Errada (RD) } \\
\text { Burro (RD) }\end{array}$ \\
\hline
\end{tabular}


Quadro 1. continuação

\begin{tabular}{|c|c|c|c|c|c|}
\hline $\begin{array}{l}\text { Código } \\
\text { do } \\
\text { aluno }\end{array}$ & Palavras & $\begin{array}{l}\text { Código } \\
\text { do } \\
\text { aluno }\end{array}$ & Palavras & $\begin{array}{l}\text { Código } \\
\text { do } \\
\text { aluno }\end{array}$ & Palavras \\
\hline AN008 & $\begin{array}{l}\text { Sem importância } \\
(\mathrm{RO}) \\
\text { Desinteresse (RO) } \\
\text { Acomodados (RO) }\end{array}$ & NA07 & $\begin{array}{l}\text { Burrice (RO) } \\
\text { Errado (RD) } \\
\text { Não sei (RDE) }\end{array}$ & A1306 & $\begin{array}{l}\text { Animal (RD) } \\
\text { Burro (RD) } \\
\text { Adição (RD) }\end{array}$ \\
\hline AN0012 & $\begin{array}{l}\text { Dificuldade (RO) } \\
\text { Burro (RD) } \\
\text { Humilde (NR) } \\
\end{array}$ & NA08 & $\begin{array}{l}\text { Falta de atenção (RO) } \\
\text { Burrice (RO) } \\
\text { Não entende (RO) }\end{array}$ & E001 & $\begin{array}{l}\text { Burro (RD) } \\
\text { Soma (RD) } \\
\text { Dúvida (NR) }\end{array}$ \\
\hline AN0014 & $\begin{array}{l}\text { Charge (RI) } \\
\text { Dificuldade (RO) } \\
\text { Não aprendizagem } \\
(\mathrm{RO})\end{array}$ & NA10 & $\begin{array}{l}\text { Conta (RD) } \\
\text { Erro (RD) } \\
\text { Burrice (RO) }\end{array}$ & & \\
\hline
\end{tabular}

Legenda: $\mathrm{RD}=$ referencial direta; $\mathrm{RI}=$ referencial indireta; $\mathrm{RDE}=$ referencial declaratória; $\mathrm{RO}=$ referencial opinativa; $\mathrm{NR}=$ não referencial.

Fonte: elaborada pelo autor.

Analisando o quadro, encontram-se: referenciais diretas, 23; referenciais indiretas, 8; referenciais opinativas, 26; referenciais declaratórias, 4 e não referenciais, 7 . As palavras que apareceram com mais frequência foram: burro + burrice, 11; soma + adição, 7; e erro, 7. O sinal + significa que as quantidades são das duas palavras juntas, sendo a primeira em maior quantidade. Contaram-se as palavras, incluindo suas variações, ou seja, erro/errado/errar. Os remas do grupo foram, portanto, burro, soma, erro com o possível dicissigno (união dos remas, formando uma proposição): o burro soma errado.

Serão analisados nove alunos para exemplificar o processo - já que não é possível analisar todos no espaço de um artigo: três alunos que associaram apenas referenciais diretas (AN005, A1305, A1306); dois (AN008, NA02) que associaram apenas referenciais opinativas; A1303 associou referenciais opinativas e uma declaratória; AN001, A1302, AN0012 e E001 que usaram entre seus remas um ou dois não referenciais ${ }^{3}$.

Observem-se as proposições que se podem gerar com os alunos que fizeram a referencialidade direta. AN005: Errado, seu burro, a adição! A1305: Soma errada, burro! A1306: Animal burro! É adição! Há pontos comuns nesses dicissignos: burro não é denotação, mas conotação; efetiva e enfaticamente com caráter ofensivo; expressam a não aceitação do erro, são opinativos. A figura foi lida em sua primeiridade, qualidade de sentimento, a onda vaga e indefinida do sentir, percepção imediata que parece ter borrado os limites entre o percepto e o percipuum. Os alunos acionaram esquemas conceituais que fizeram emergir elementos interpretativos, e o

\footnotetext{
${ }^{3}$ As letras A, AN, NA e E configuram grupos distintos de alunos pesquisados em anos diferentes.
} 
juízo perceptivo se expressou pela indignação com o erro. O interpretante dinâmico ocorre em seu primeiro nível, o emocional, e parece dominar o processo interpretativo, pois o energético apresenta uma reação ativa de indignação e esta culmina no efeito lógico da interpretação, pois a palavra burro perde seu caráter denotativo para se apropriar do conotativo. Sugere mergulho no emocional e afastamento da referencialidade. Qual seria a reação desses alunos, no futuro, como professores, diante do erro de um aluno? Focados no erro, não veem que é apenas uma charge, uma brincadeira. O teste de realidade falhou: a inibição deveria tê-los levado a perceber a charge como brincadeira, possibilitando uma percepção mais próxima da realidade. Porém embarcaram na doxa, na opinião.

Pensa-se, aqui, no platonismo como fundamento dessa expressão opinativa. Parafraseando Moravcsik (2006), faltou-lhes o entendimento, pois assumiram a doxa como estado epistêmico básico. "[...] quando estamos num estado de sonho e consideramos as visões e os sons como os elementos básicos da realidade, então o máximo de que somos capazes é a doxa" (MORAVCSIK, 2006, p. 47). A opinião traz a confusão entre aparência e realidade, já que é aprendida por persuasão e não se deixa levar pelo racional. Pode-se pensar, seguindo o platonismo, que a técnica dos algoritmos tradicionais se enquadra na doxa: “[...] O entendimento é adquirido por 'reminiscência', enquanto, no caso típico, opiniões são adquiridas por persuasão de vários tipos: por exemplo, exercícios de repetição em matemática simples [...]" (MORAVCSIK, 2006, p. 54). A aritmética elementar é prática comum humana: “[...] A maioria de nós sabe como somar, subtrair, e assim por diante, mas, de acordo com Platão, apenas uns poucos entre nós realmente entendem do que se trata a matemática" (MORAVCSIK, 2006, p. 55), pois, geralmente, é-se persuadido a aprendê-la.

A opinião é julgar pelas aparências, argumenta Platão (2001), os amantes dos espetáculos se deixam prender pelas aparências. Carvalho (2013), a partir do pensamento de Debord (2000, p. 23 apud CARVALHO, 2013, p. 595), para quem na contemporaneidade "estar na imagem é existir", propõe uma pedagogia cultural crítica das imagens. Porém, os alunos pesquisados parecem ter sentido que estar na imagem é um existir, sugerindo falta de distanciamento crítico, pois o erro matemático levou-os à indignação. Para Debord (2000, p. 188 apud CARVALHO, 2013, p. 595, grifo do autor), "a imagem construída e escolhida por outra pessoa se tornou a principal ligação do indivíduo com o mundo": os alunos, falhando o teste de realidade, se apropriaram da imagem ao se indignarem.

Perrone-Moisés (2011, p. 175) fala da doxa, como

[...] o lugar de uma fala mais geral, constituída de clichês sociais, dos quais depende o Ideal do Eu do locutor. Segundo Freud, o Ideal do Eu depende de "formações coletivas", de "submultidões". É aquilo que Roland Barthes, inspirando-se em Brecht, chamou de Doxa: a opinião corrente, a voz do povo, a ideologia no mau sentido.

A doxa é o imaginário socializado, falso código e lei falsa, não operando na ordem simbólica por ser um simulacro. Ela lembra Lacan e a doxa como estereótipo, como bobagem, que é uma forma de coletivizar o significante.

Nas dissertações dos alunos (Minha história com a matemática), há um ponto em comum: os três gostavam da matemática e, em algum momento, passaram a ter dificuldades. 
A1305: "Quando criança gostava de matemática, era divertido, tinha joguinhos, brincadeiras e interação com a professora [...] Comecei a temer a disciplina de matemática bem mais tarde, já no fundamental”. AN005: "Conheço a matemática desde a 1. série do ensino fundamental, sempre gostei da matéria". Ao começar a Faculdade de Matemática, conheceu "[...] a verdadeira matemática, me identifiquei com algumas matérias, como matemática financeira, cálculo e fundamentos de matemática elementar, e dificuldades com geometria e fisica, com o pouco conhecimento da matemática fundamental, desisti do curso no 1. ' semestre". [AN005].

A1306: "A matemática em minha vida, pode se dizer que sempre foi um divisor de águas, nunca tive problemas em entender a matemática até certo ponto em meu currículo escolar". Mais tarde, ele começou outra Faculdade: "[...] decidi faz̧er o ensino superior, e logo no $1 .^{\circ}$ semestre tive muita dificuldade em relembrar e entender a fórmula de Bhaskara, e por muito pouco não fiquei em DP [disciplina pendente]".

Freud (1976b, p. 299) diz que "é evidente que uma precondição para o estabelecimento do teste de realidade consiste em que objetos, que outrora trouxeram satisfação real, tenham sido perdidos". Nos três casos, o prazer primordial com a matemática foi perdido. O autor informa: "Julgar é uma continuação, por toda a extensão das linhas da conveniência, do processo original através do qual o ego integra coisas a si ou as expele de si, de acordo com o princípio de prazer". (FREUD, 1976b, p. 299).

A1306 diz:

Da pré-escola não me recordo, porém, no ensino fundamental, tive um professor que na minha vida era um terror. Ele era o queridinho de todos na escola e muito animado, porém, como eu já tinha dificuldade, ele gostava de complicar ainda mais. A forma de ele passar o conteúdo era para as crianças que realmente dominavam o assunto, porque muitos não conseguiam ir bem. Uma linguagem difícil de entender e eu tinha vergonha de tirar dúvidas porque parecia que todas eram bobas e, se en expunha, continuava com ela. Fazia questão de corrigir as provas e todos já sabiam a sua nota, o que não era muito legal.

Ele anota o erro da Figura 1 como desinteresse e acomodação, porém defensivamente e condescendentemente não lhes atribui importância.

A1303 escreveu os seguintes remas: excluído, rejeitado, difícil, que pode gerar o dicissigno: ser excluido e rejeitado é difícil. As duas primeiras palavras são referenciais opinativas e a terceira é referencial declaratória. Esta última contamina o dicissigno, transformando-o em declaratório. Se ele tivesse usado uma referencial direta, por exemplo, lousa, o dicissigno seria: excluído e rejeitado na lousa, tornando-o um dicissigno opinativo. Em sua história com a matemática, narra: "Não tenho lembranças boas a respeito da minha vida e a matemática. Minha história com a matemática não foi nenhum conto de fadas, pelo contrário, foi uma história de terror". Fala da professora estressada que gritava demais e que "ficava bem quietinha com minhas dúvidas, no canto, sem perturbar ninguém. Até que um dia ela me enxergou e eu virei a bola da vež". Vê, portanto, os burros como rejeitados, excluídos e se identifica com eles.

AN001, A1302, AN0012 e E001 usaram também não referenciais. AN001 escreveu os remas: matemática, animação, incentivo. A primeira é uma referencial indireta, as outras duas são 
não referenciais. O dicissigno que se pode formar: matemática é animação e incentivo. Os remas de A1302 foram: rotulação, conbecimento, atenção. Uma referencial opinativa e duas não referenciais. O dicissigno constituído: rotulação do conhecimento. Atenção! Para AN0012, as palavras foram: dificuldade, burro, bumilde. Uma referencial opinativa, outra referencial direta e a terceira, não referencial. O dicissigno: dificuldade do burro bumilde. E001 escreveu duas referenciais diretas e uma não referencial: burro, soma, dúvida, cujo dicissigno pode ser: burro soma com dúvida. Remas isolados não transmitem informação, mas o exercício de transformação em dicissignos, cria linguagem discursiva interpretável. Os quatro dicissignos são opinativos.

Ao fazer a varredura da imagem, AN001 sugere ter sentido um baque e fugido para uma referencial indireta: matemática. Freud (1915 apud JORGE, 2008, p. 24) diz que o fundamento do recalque é "manter algo a distância". Além disso, a associação livre como regra fundamental da psicanálise leva a se produzir derivados do recalcado. A figua 1, um estímulo externo, provocou desprazer e, portanto, recalque da pulsão, do estímulo interno. Uma das possibilidades de afastamento do estímulo interno desprazeroso é usar o juízo de condenação, capaz de substituir, intelectualmente, o recalque, controlando-o, dosando-o. "[...] Se uma impulsão dotada de uma tendência para transformar-se em ato pode ser afastada, rejeitada, condenada, torna-se então impotente para realizar-se e só pode persistir na qualidade de lembrança" (RABINOVITCH, 2001, p. 58). AN001 escreve em sua história com a matemática: "Já na primeira série minha experiência já não foi muito agradável, pois a professora era muito rígida, e, devido a isso, en tive um bloqueio com a matemática, que me prejudicou um pouco no colegial, e na vida em geral'. Talvez por isso opine que matemática é animação e incentivo, desculpando-se pelo bloqueio.

A1302 chama a atenção para a rotulação do conhecimento. Na sua história com a matemática, disserta da importância que tem na vida, seus benefícios e termina dizendo: "Tive momentos embaraçosos com a matemática, mas hoje estou pegando o 'fio da meada", contudo não explicitou esses momentos. Implícito o juízo de condenação no seu dicissigno.

Para AN0012, há a dificuldade do burro humilde. Esse dicissigno parece remeter para o sociologismo reinante no meio escolar de que a não aprendizagem ocorre em razão da pobreza, um substrato das epistemologias apriorista e empírica. Diz: "Meu trauma do agora chamado ensino fundamental foi justamente a problemática matemática que sempre somaram as minhas dúvidas, e a tabuada que só multiplicon o meu trauma”.

E001 opina que burro soma com dúvida. Seu juízo de condenação conclama o erro como burrice. Esse aluno narra sua história com a matemática no meio rural. Seu contato com os números foi observando os pais contando espigas de milho e batatas-doces para as fogueiras juninas. Narra as associações que fez dos números com os dedos e gravetos, que teve bons professores e seu único problema foram as contas de divisão em que teve "certa dificuldade para fazer os cálculos de emprestar".

Para combater a opinião, a doxa, que evidencia sua essência fraudulenta, pode-se recorrer à "análise sistemática da linguagem" e ao pensamento psicanalítico, informa Telles (2006, p. 144). Na "sociedade do espetáculo", diz o autor, não importam os fatos, mas suas versões, os simulacros, as imagens. O pensamento psicanalítico auxilia a compreender as "vinculações complexas entre palavra e verdade.” (TELLES, 2006, p. 144). A verdade do sujeito se encontra envolvida pelas doxa do Outro (alienação no Outro). "Dessa forma, a procura da verdade feita pela psicanálise tem um trajeto muito próprio, numa inédita combinação de Alethéia e Doxa, produzindo a verdade única do inconsciente.” (TELLES, 2006, p. 144, grifos do autor). Este 
artigo combinando semiótica e psicanálise buscou desvendar índices dessa "verdade" inconsciente, procurando o interpretante final.

\section{Considerações}

Os alunos pesquisados associaram a maior quantidade de remas (26) como referenciais opinativas. A união dos remas que mais apareceram também produziu um dicissigno opinativo: o burro soma errado.

A teoria da percepção peirceana possibilitou radiografar como a maioria fez a varredura visual da Figura 1. Ao verem a figura, o percepto captou o sentido geral expresso, filtrando o estímulo e convertendo-o em percipuum. O primeiro nível dessa filtragem produziu a onda vaga e indefinida do sentimento, e o rema com maior citação foi burro; o segundo nível levou à percepção do algoritmo errado, provocando a surpresa, o choque: como errar uma soma tão simples? Surge o percipuum, capturado pelos esquemas mentais interpretativos dos alunos, que reconheceram na figura a burrice, e cada um, dependendo do efeito colateral produzido, fez referências diretas, indiretas, opinativas, declaratórias ou não referenciais. Mas, no geral, predominaram as referenciais opinativas. O juízo perceptivo é produto de sua interpretação. $\mathrm{O}$ interpretante dinâmico esteve presente em todo o processo perceptivo. O que prevaleceu foi a opinião: o burro soma errado.

A opinião expressa uma falha no teste de realidade. A Figura 1 seria uma brincadeira entre duas torcidas, mas sua representação visual expressa a burrice. A imagem produziu lembranças desprazerosas nos alunos. Poucos conseguiram referenciá-la diretamente e, mesmo assim, predominou a opinião, que pode ser vista como uma fuga (alucinação), prisão ao imaginário. Falhou o teste de realidade cuja microscopia de seus elementos se tentou efetuar: falha na inibição que possibilitaria não se deixar envolver pelo emocional. Falha, também, de certa maneira a atenção, não se levando em conta a realidade retratada pela figura. O julgar se aliou ao platonismo; a aparência sobrepujou, deixando prevalecer a representação subjetiva em detrimento da realidade. A ação motora exercida, escrever os remas associativos, exprimiu os efeitos colaterais do platonismo expressos na doxa.

O juízo condenatório emerge e o dicissigno transparece como expressão discursiva dos alunos: o burro soma errado. Não se vê um simples erro, mas o erro. Não sabem nem somar nem subtrair, prática comum elementar, como já reconhecia Platão. O erro é indesculpável. A charge brincou com a burrice, mas ela expressa uma representação social de uma maneira de se ver o erro nas produções matemáticas. O pensamento matemático dos alunos pesquisados apenas expressa isso. Contudo, proclama também o recalcado: os derivados do recalcado emergem, primeiramente nos remas e se materializam nos dicissignos, possibilitando essa e outras interpretações possíveis.

Por fim, esta foi uma leitura semiótico-psicanalítica em que se buscou o nível do interpretante final de uma das representações visuais da burrice. Procurou-se elencar dados para se entender, em futuras pesquisas, a burrice como uma construção de epistemologias do senso comum, vendo-a como produtos inatistas ou empiristas. 
Análise semiótico-psicanalítica de uma representação visual da burrice ...

\section{Referências}

ARNHEIM, R. Arte \& percepção visual: uma psicologia da visão criadora. 5. ed. São Paulo: Pioneira, 1989.

. O poder do centro. Lisboa: Edições 70, 1990.

BARTHES, R. A câmara clara: nota sobre a fotografia. Rio de Janeiro: Nova Fronteira, 1984.

BECKER, F. Epistemologia do professor de matemática. Petrópolis: Vozes, 2012.

BIAJONE, J. A abordagem do trabalho de projetos na formação estatística do pedagogo. In: ENCONTRO NACIONAL DE EDUCAÇÃO MATEMÁTICA (ENEM), 9., Belo Horizonte, 2006. Anais... Belo Horizonte: UniBh, 2006, p. 1-16. Disponível em: <www. sbembrasil.org.br/files/ix_enem/Comunicacao_Cientifica/Trabalhos/CC21255094826T. rtf>. Acesso em: 05 jul. 2015.

CARVALHO, A. F. Educação e imagens na sociedade do espetáculo: as pedagogias culturais em questão. Educação \& Realidade, Porto Alegre, v. 38, n. 2, p. 587-602, 2013. Disponível em: <http://seer.ufrgs.br/index.php/educacaoerealidade/article/view/21437/25742>. Acesso em: 17 jan. 2017.

CATHARINO, A. L. O descritivo no ensino: limites e possibilidades. 2007. $131 \mathrm{f}$.

Dissertação (Mestrado em Língua Portuguesa) - Pontifícia Universidade Católica de São Paulo, São Paulo, 2007.

CHAVES, M. F. M. C. Do aborrecer ao “emburrecer”: de onde vem a burrice? 2001. 97 f. Dissertação (Mestrado em Engenharia de Produção) - Universidade Federal de Santa Catarina, Florianópolis, 2001.

DONDIS, D. A. Sintaxe da linguagem visual. São Paulo: Martins Fontes, 1991.

FIGUEIRA contraria matemática e mantém ascensão na tabela. Diário Catarinense, Florianópolis, [17 jul. 2008]. Disponível em: <http://www.clicrbs.com.br/especial/sc/ qualidade-de-vida-sc/19,0,2050965, Figueira-contraria-matematica-e-mantem-ascensao-natabela.html>. Acesso em: 18 jan. 2017.

FIGUEIREDO, L. C. A clínica psicanalítica a partir de Melanie Klein. O que isto pode significar? Jornal de Psicanálise, São Paulo, v. 39, n. 71, p. 125-150, dez. 2006.

Disponível em: <http://pepsic.bvsalud.org/scielo.php?script=sci_arttext\&pid= S010358352006000200008>. Acesso em: 17 jan. 2017.

FREUD, S. A negativa. In: Edição standard brasileira das obras psicológicas completas de Sigmund Freud. Rio de Janeiro: Imago, 1976b. v. 19, p. 289-300.

. Novas conferências introdutórias sobre a psicanálise. In: Edição standard

brasileira das obras psicológicas completas de Sigmund Freud. Rio de Janeiro: Imago, 1976a. v. 22, p. 13-220.

Sobre a psicopatologia da vida cotidiana. In: Edição standard brasileira das obras psicológicas completas de Sigmund Freud. Rio de Janeiro: Imago, 1987. v. 6. 
JORGE, M. A. C. Fundamentos da psicanálise de Freud a Lacan: vol. 1: as bases conceituais. 5. ed. Rio de Janeiro: Zahar, 2008.

Fundamentos da psicanálise de Freud a Lacan: vol. 2: a clínica da fantasia. Rio de Janeiro: Zahar, 2010.

LEMOS, I. S. A comunicação não verbal: um estudo de caso. UNIrevista, São Leopoldo, v. 1, n. 3, p. 1-12, 2006.

MORAVCSIK, J. Platão e o platonismo. São Paulo: Loyola, 2006.

NÖTH, W. Panorama da semiótica: de Platão a Peirce. São Paulo: Annablume, 1995.

PEIRCE, C. S. Semiótica. São Paulo: Perspectiva, 1977.

PERRONE-MOISÉS, L. A fala esvaziada em Nelson Rodrigues. In: PASSOS, C. R. P.; ROSENGAUM, Y. (Org.). Escritas do desejo: crítica literária e psicanálise. Cotia: Ateliê Editorial, 2011. p. 161-176.

PLATÃO. República. 9. ed. Lisboa: Fundação Calouste Gulbbenkian, 2001.

PORCHAT, P. Freud e o teste de realidade. São Paulo: Casa do Psicólogo: FAPESP, 2005.

RABINOVITCH, S. A foraclusão: presos do lado de fora. Rio de Janeiro: Jorge Zahar, 2001.

RAMOS, J. L. Sergei Eisenstein. Lisboa: Livros Horizonte, 1982.

RECTOR, M.; TRINTA, A. R. Comunicação não-verbal: a gestualidade brasileira. 2. ed. Petrópolis: Vozes, 1986.

SANTAELLA, L. Matrizes da linguagem e pensamento: sonora, visual, verbal. 3. ed. São Paulo: Iluminuras: FAPESP, 2005a.

Semiótica aplicada. São Paulo: Pioneira Thomson Learning, 2005b.

SIGNORINI, M. B. Crianças, algoritmos e sistema de numeração decimal. 2007. 124 f. Dissertação (Mestrado em Educação) - Universidade Estadual de Maringá, Maringá, 2007.

TELLES, S. Visitas às casas de Freud e outras viagens. São Paulo: Casa do Psicólogo, 2006.

VASCONCELLOS, M.; BITTAR, M. A formação dos professores que ensinam matemática na educação infantil e nos anos iniciais: um estudo sobre a produção dos eventos realizados no ano 2006. In: ENCONTRO NACIONAL DE EDUCAÇÃO MATEMÁTICA (ENEM), 9., Belo Horizonte, 2006. Anais... Belo Horizonte, UniBh, 2006. Disponível em: <www. sbembrasil.org.br/files/ix_enem/Comunicacao_Cientifica/Trabalhos/CC99036649749T. doc >. Acesso em: 04 jul. 2015.

Artigo recebido em 17/12/2015. Aceito em 31/07/2016.

Endereço para contato: Universidade Paulista (UNIP), Instituto de Ciências Humanas, Avenida Francisco Manoel, s/n, Santos, SP, CEP1045-300, Brasil. 